\title{
Does the psychophysical method affect the time error?
}

\author{
VALENTINA FANTON \\ University of Padua, Padua, Italy \\ (Sergio C. Masin, Sponsor)
}

\begin{abstract}
The time error (TE) in the comparison of durations of visual stimuli has been studied here, varying systematically the stimulus duration and the interstimulus interval (ISI). The method of constant stimuli was used. The results showed that for short stimulus durations $(.26$ and $.38 \mathrm{sec})$, positive TEs increased as the ISI increased, and that for long durations (1.12 and $5.6 \mathrm{sec}$ ), negative TEs decreased as the ISI increased. The same trend of results as that obtained in the present Experiment 3 has previously been reported by researchers who used the method of reproduction. The conclusion is reached that the method of constant stimuli and the method of reproduction are consistent methods when only the trend of results is considered.
\end{abstract}

When two stimuli with equal intensity are presented successively for comparison, the subject may overestimate or underestimate one stimulus with respect to the other. This effect is called the time error (TE). When the subjective intensity of a variable (V) stimulus is judged to be equal to that of a standard (S) stimulus, a negative (positive) TE indicates that $\mathrm{V}$ is physically smaller (greater) than $S$.

In tasks that involve the scaling or the comparison of durations presented successively, it has been reported that the interstimulus interval (ISI) and the duration of the compared stimuli are two important variables influencing the TE (Nakajima, 1958; Stott, 1935; Woodrow, 1935; Woodworth \& Schlosberg, 1954). Figure 1 shows the results of an experiment by Munari and Altichieri (1954), in which the subject had to reproduce time intervals delimited by two sounds. Intervals had to be reproduced after ISIs varying from 0 to $20 \mathrm{sec}$. Figure 2 shows the results obtained by Kozaki (1977) in an independent experiment in which durations of a light had to be reproduced. He used ISIs from 0 to $9 \mathrm{sec}$. In both Figures 1 and 2, the TE percentage is represented as a function of the ISI, using the duration of $S$ as a parameter. The TE percentage is defined in both figures as $100\left(T_{r}-\right.$ $\left.T_{s}\right) / T_{s}$, where $T_{r}$ is the point of subjective equality and $T_{s}$ is the duration of $S$. The general trend of results in Figures 1 and 2 is similar-that is, the TE percentage increases in absolute value as the ISI increases and as the stimulus duration decreases. However, the result when the duration was $1.5 \mathrm{sec}$ in Munari and Altichieri's (1954) experiment contrasts with the results in Kozaki's (1977) experiment when the durations were 1 or $2 \mathrm{sec}$.

I thank S. Bettella for having written the computer programs used in the experiments reported here. Coriespondence should be addressed to V. Fanton, Via San Zeno 30/bis, 37053 Cerea (VR), Italy.
In an experiment in which subjects had to compare the durations of two lights, Jamieson and Petrusic (1975a, 1975b) obtained data partially in disagreement with those reported by Munari and Altichieri (1954) and by Kozaki (1977). Jamieson and Petrusic reported that the TE decreased in magnitude as the ISI increased, for both short (around $0.3 \mathrm{sec}$ ) and long (around $5 \mathrm{sec}$ ) durations. They also reported that the TE was positive when the compared durations were short, and negative when the durations were both short and long. However, Jamieson and Petrusic's results will not be considered further here, because they were not obtained through the use of a complete experimental design.

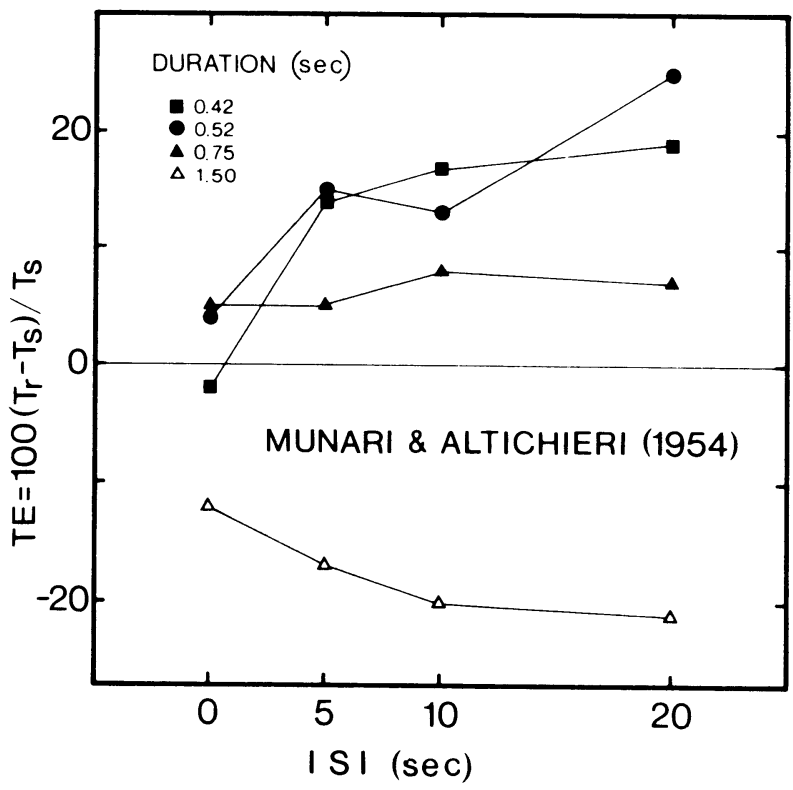

Figure 1. Results obtained by Munari and Altichieri (1954). The TE percentage is represented as a function of ISI. The parameter is the duration of $\mathrm{S}$. 


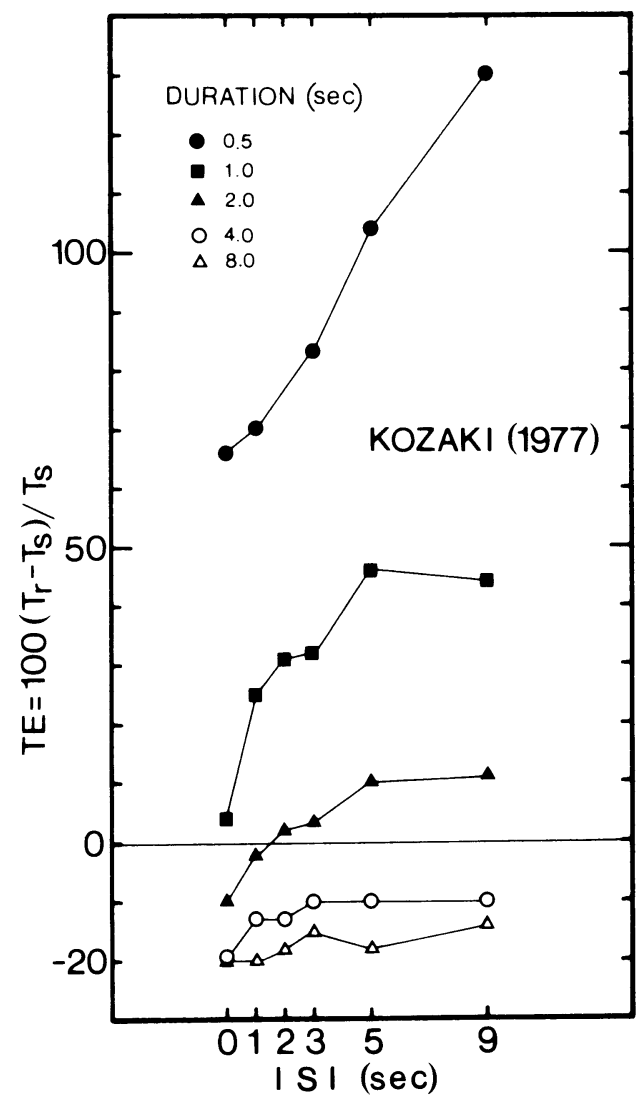

Figure 2. Results obtained by Kozaki (1977). The TE percentage is represented as a function of ISI. The parameter is the duration of $\mathbf{S}$.

Figure 3 depicts results obtained by Hellström (1979) when subjects had to compare the loudness of two sounds presented successively. The TE is represented as a function of the ISI, and the parameter is the duration of the stimuli. The TE was computed on the basis of the Thurstonian model for comparative judgment (Torgenson, 1958, chap. 10). As may be seen, Hellström's (1979) results, which were obtained by the method of paired comparisons, are opposite to the results reported by Munari and Altichieri (1954) and by Kozaki (1977), which were obtained through the method of reproduction.

The following possible reasons for these opposite results may be distinguished: (1) the fact that the use of the paired comparisons method implied (a) a comparison between stimuli and (b) the uncontrolled occurrence of the asymmetry effect (Masin \& Agostini, 1989; Masin, Fanton, \& Crestoni, 1988), and/or (2) the fact that in Hellström's (1979) experiment, subjects judged loudness differences instead of duration differences.

The following experiment was undertaken to test whether the discrepancy between Hellström's (1979) and Kozaki's (1977) results could be due to a difference in kind of judgment (comparison versus reproduction). For this purpose, the method of constant stimuli was used, taking extreme care to try to minimize the asymmetry effect.

\section{EXPERIMENTS 1 AND 2}

The purpose of these experiments was to find the Ss and the ranges of Vs for each $\mathrm{S}$ that minimized the asymmetry effect.

\section{Method}

Subjects. The subjects were university students who were asked to take part in the experiment as they entered the psychology department at the University of Padua. There were 20 subjects in Experiment 1 and 10 in Experiment 2.

Stimuli. The stimuli were $0.4 \times 0.4 \mathrm{~mm}$ squares in the middle of a $17.5 \times 23.5 \mathrm{~cm}$ monitor screen. Each subject viewed the stimuli from a distance of about $50 \mathrm{~cm}$ in a room with moderate illumination. The method of constant stimuli was used. The squares were shown successively in pairs. The first square in a pair was the $S$, and the second was a V. There were five Vs for each of five Ss. Tables 1 and 2 show the durations used in Experiments 1 and 2, respectively. The durations for Experiment 2 were chosen on the basis of the results of Experiment 1. The ISIs were $.1, .2, .5,1$, and $5 \mathrm{sec}$ in both experiments. The durations of squares and the ISIs were controlled by an Apple microcomputer

Procedure. Each observer was shown once all the 125 combinations of five Ss, five Vs, and five ISIs, in random order. The task of the subject was to report which one of the two stimuli in a pair lasted longer. Each pair of stimuli was displayed when the subject pressed a key. The subject was not told which one was $\mathrm{S}$ or $\mathrm{V}$. The subject was urged to be as accurate as possible, not to make mental computations, and to respond as spontaneously as possible.

\section{Results}

The results of Experiment 1 are reported in Table 3, where the proportions of the "longer" response are listed for each combination of S, V, and ISI. As can be seen, some psychometric functions are displaced far toward the upper part of the continuum of Vs, and some are rather flat. From these data, new Ss and Vs were chosen for Experiment 2. The Ss and the Vs were chosen in order to obtain psychometric functions with proportions of the

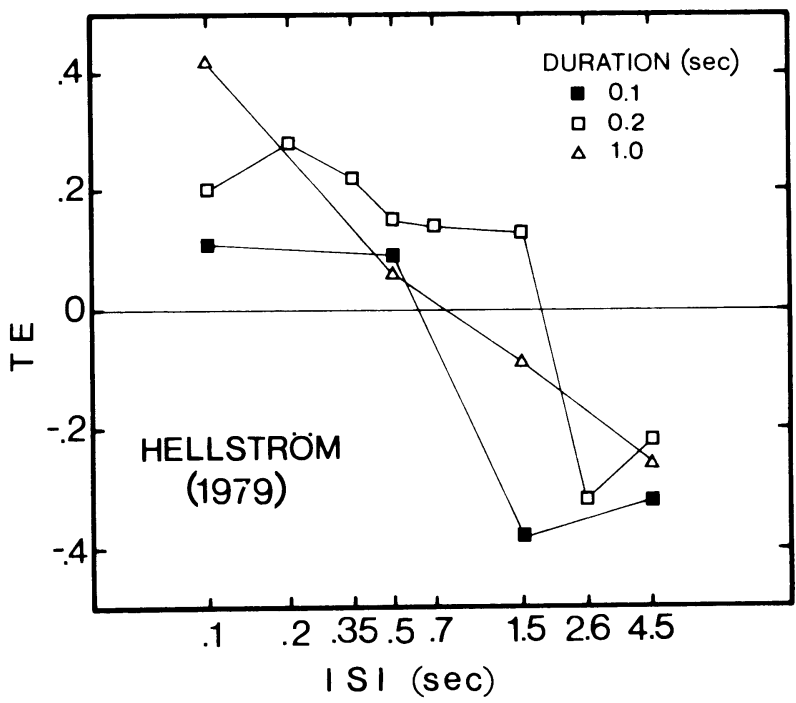

Figure 3. Results obtained by Hellström (1979). The TE, which was estimated using the Thurstonian model for comparative judgment, is represented as a function of ISI. The parameter is the duration of $S$. 
Table 1

Durations of Stimuli Used in Experiment 1 (in sec)

\begin{tabular}{cccccc}
\hline $\mathrm{S}$ & $\mathrm{V} 1$ & $\mathrm{~V} 2$ & $\mathrm{~V} 3$ & $\mathrm{~V} 4$ & $\mathrm{~V} 5$ \\
\hline .10 & .02 & .06 & .10 & .14 & .18 \\
.20 & .12 & .16 & .20 & .24 & .28 \\
.50 & .42 & .46 & .50 & .54 & .58 \\
1.00 & .88 & .94 & 1.00 & 1.06 & 1.12 \\
5.00 & 4.40 & 4.70 & 5.00 & 5.30 & 5.60 \\
\hline
\end{tabular}

Table 2

Durations of Stimuli Used in Experiment 2 (in sec)

\begin{tabular}{cccccc}
\hline$S$ & V1 & V2 & V3 & V4 & V5 \\
\hline .02 & .02 & .09 & .16 & .23 & .30 \\
.12 & .12 & .19 & .26 & .33 & .40 \\
.48 & .18 & .28 & .38 & .48 & .58 \\
1.02 & .72 & .82 & .92 & 1.02 & 1.12 \\
5.60 & 3.20 & 3.80 & 4.40 & 5.00 & 5.60 \\
\hline
\end{tabular}

Table 3

Results of Experiment 1

\begin{tabular}{|c|c|c|c|c|c|c|}
\hline \multirow[b]{2}{*}{ ISI } & \multirow[b]{2}{*}{$S$} & \multicolumn{5}{|c|}{$\begin{array}{l}\text { Proportion of the "Longer" } \\
\text { Response for Each V }\end{array}$} \\
\hline & & $\mathrm{V} 1$ & $\mathrm{~V} 2$ & V3 & $\mathrm{V} 4$ & V5 \\
\hline .1 & $\begin{array}{r}.1 \\
.2 \\
.5 \\
1.0 \\
5.0\end{array}$ & $\begin{array}{l}.20 \\
.35 \\
.50 \\
.55 \\
.70\end{array}$ & $\begin{array}{l}.25 \\
.50 \\
.45 \\
.40 \\
.75\end{array}$ & $\begin{array}{l}.35 \\
.55 \\
.65 \\
.40 \\
.80\end{array}$ & $\begin{array}{l}55 \\
.55 \\
.65 \\
.70 \\
.70\end{array}$ & $\begin{array}{l}.55 \\
.65 \\
.65 \\
.65 \\
.90\end{array}$ \\
\hline .2 & $\begin{array}{r}.1 \\
.2 \\
.5 \\
1.0 \\
5.0\end{array}$ & $\begin{array}{l}.15 \\
.35 \\
.45 \\
.45 \\
.60\end{array}$ & $\begin{array}{l}.30 \\
.60 \\
.70 \\
.85 \\
.65\end{array}$ & $\begin{array}{l}.70 \\
.50 \\
.65 \\
.80 \\
.85\end{array}$ & $\begin{array}{l}.50 \\
.65 \\
.50 \\
.75 \\
.95\end{array}$ & $\begin{array}{l}.70 \\
.80 \\
.85 \\
.85 \\
.90\end{array}$ \\
\hline .5 & $\begin{array}{r}.1 \\
.2 \\
.5 \\
1.0 \\
5.0\end{array}$ & $\begin{array}{l}.10 \\
.25 \\
.40 \\
.45 \\
.80\end{array}$ & $\begin{array}{l}.30 \\
.30 \\
.35 \\
.60 \\
.80\end{array}$ & $\begin{array}{l}.45 \\
.35 \\
.45 \\
.75 \\
.85\end{array}$ & $\begin{array}{l}.65 \\
.70 \\
.60 \\
.70 \\
.95\end{array}$ & $\begin{array}{l}.85 \\
.70 \\
.65 \\
.85 \\
.95\end{array}$ \\
\hline 1.0 & $\begin{array}{r}.1 \\
.2 \\
.5 \\
1.0 \\
5.0\end{array}$ & $\begin{array}{l}.00 \\
.30 \\
.35 \\
.40 \\
.75\end{array}$ & $\begin{array}{l}.40 \\
.40 \\
.30 \\
.60 \\
.90\end{array}$ & $\begin{array}{l}.65 \\
.30 \\
.45 \\
.60 \\
.90\end{array}$ & $\begin{array}{l}.60 \\
.55 \\
.35 \\
.70 \\
.95\end{array}$ & $\begin{array}{l}.60 \\
.60 \\
.80 \\
.65 \\
.90\end{array}$ \\
\hline 5.0 & $\begin{array}{r}.1 \\
.2 \\
.5 \\
1.0 \\
5.0 \\
\end{array}$ & $\begin{array}{l}.00 \\
.25 \\
.35 \\
.50 \\
.55\end{array}$ & $\begin{array}{l}.00 \\
.20 \\
.35 \\
.60 \\
.75\end{array}$ & $\begin{array}{l}.15 \\
.25 \\
.35 \\
.55 \\
.80\end{array}$ & $\begin{array}{l}.50 \\
.30 \\
.50 \\
.60 \\
.90\end{array}$ & $\begin{array}{l}.50 \\
.50 \\
.50 \\
.50 \\
.85\end{array}$ \\
\hline
\end{tabular}

Note-ISIs and Ss are in seconds.

Table 4

Durations of Stimuli Used in Experiment 3 (in sec)

\begin{tabular}{cccccc}
\hline S & V1 & V2 & V3 & V4 & V5 \\
\hline .26 & .12 & .19 & .26 & .33 & .40 \\
.38 & .18 & .28 & .38 & .48 & .58 \\
1.12 & .72 & .82 & .92 & 1.02 & 1.12 \\
5.60 & 3.20 & 3.80 & 4.40 & 5.00 & 5.60 \\
\hline
\end{tabular}

"longer" response for V1 and V5 very close to 0 and 1 , respectively.

The results of Experiment 2 are not reported, since the new data gave the same kind of information as that supplied by Table 3. From the data obtained from Experiment 2, the final Ss and Vs for use in Experiment 3 were chosen. The choice was made according to the same principle that was used to choose the Ss and Vs for Experiment 2 .

\section{EXPERIMENT 3}

\section{Method}

Subjects. The subjects were $\mathbf{4 0}$ university students who did not participate in Experiments 1 and 2.

Stimuli and Procedure. The stimuli and procedure were the same as in Experiments 1 and 2, except that the Ss and the Vs were now those listed in Table 4. The ISIs were $.2, .5,1$, and $5 \mathrm{sec}$.

\section{Results}

The results are shown in Figure 4. The TE percentage is represented as a function of the ISI, using the duration of $S$ as a parameter. The mean points of subjective equality, $T_{c}$, were obtained by fitting the psychometric functions by the weighted least-squares method. A $4 \times 4$ (ISI by duration of $S$ ) analysis of variance was made, using the individual points of subjective equality as scores, which were obtained by a modified version of the method of transitions (Masin, 1989). The main effects due to ISI and the duration of $S$, and the interaction, were highly significant $[F(3,117)=199.9, p<.0001, F(3,117)=$

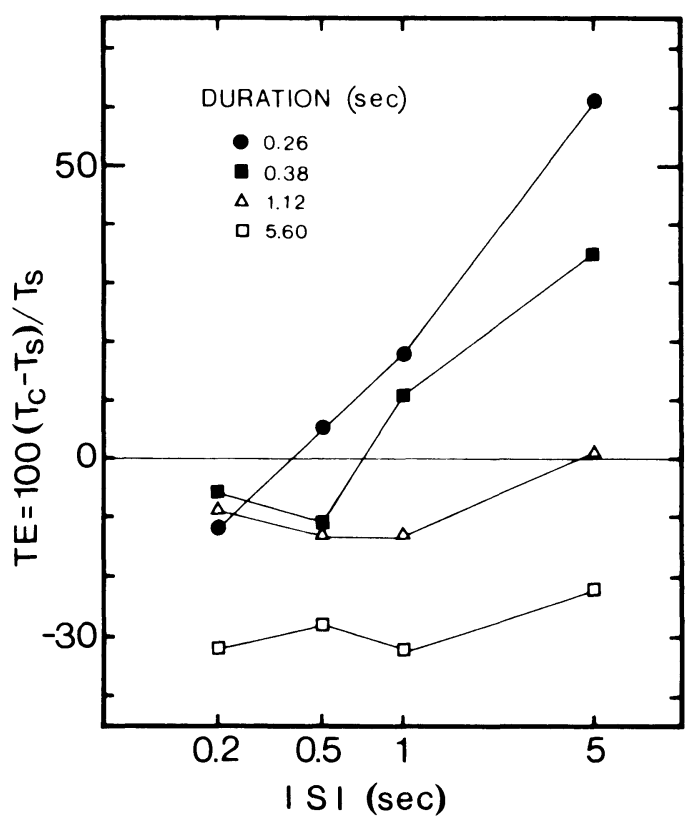

Figure 4. Results obtained from Experiment 3 reported here. The TE percentage is represented as a function of ISI, using the duration of $\mathbf{S}$ as a parameter. 
$251.9, p<.0001$, and $F(9,351)=44.6, p<.0001$, respectively].

\section{DISCUSSION}

As can be seen, the trend of results depicted in Figure 4 is in agreement with the trend of results found by Kozaki (1977; see Figure 2 here). It may therefore be concluded that the opposition between Hellström's (1979) and Kozaki's results cannot be ascribed to a difference in the kind of judgment (comparison vs. reproduction). The reason why Hellström's (1979) trend of results is opposite to that depicted in Figures 2 and 4 could then be the fact that Hellström used loudness instead of duration as an attribute for the comparative judgment. Clearly, the psychophysical method has some effect on the TE, since the data in Figures 2 and 4 do not overlap. Perhaps this difference in results is due to a motor error or some other kind of bias (Guilford, 1954).

\section{REFERENCES}

Guilford, P. (1954). Psychometric methods. New York: McGraw-Hill. Hellström, A. (1979). Time errors and differential sensation weighting. Journal of Experimental Psychology: Human Perception \& Performance, 5, 460-477.

Jamieson, D. G., \& Petrusic, W. M. (1975a). The dependence of timeorder error direction on stimulus range. Canadian Journal of Psychology, 29, 175-182.

Jamieson, D. G., \& Petrusic, W. M. (1975b). Presentation order effects in duration discrimination. Perception \& Psychophysics, 17, 197-202.
KozAKI, T. (1977). Time order error in reproduction of durations. (Rep. No. 9). Yokohama, Japan: Keio University, Psychological Laboratory on the Hiyoshi Campus.

Masin, S. C. (1989). A simplified version of the method of transitions. Perceptual \& Motor Skills, 68, 131-135.

Masin, S. C., \& AGostinI, A. (1989). The asymmetry and presentationorder effects in the method of pair comparisons. Unpublished manuscript.

Masin, S. C., Fanton, V., \& Crestoni, L. (1988). An experimental study of the asymmetry effect in the method of constant stimuli. Psychological Research, 50, 181-182.

MUNARI, I., \& AlTICHIERI, L. (1954). Trasformazioni nella riproduzione di brevi intervalli temporali [Transformations in the reproduction of short time intervals]. In V. Lazzeroni (Ed.), Atti del X Convegno degli Psicologi Italiani (p. 163). Florence, Italy: Editrice Universitaria.

NaKaJima, S. (1958). The time-error in the successive comparison of tonal durations. Japanese Journal of Psychology, 29, 18-28.

STorT, L. H. (1935). Time-order errors in the discrimination of short tonal durations. Journal of Experimental Psychology, 18, 741-766.

ToRgenson, W. S. (1958). Theory and methods of scaling. New York: Wiley.

WoodRow, H. (1935). The effect of practice upon time-order errors in the comparison of temporal intervals. Psychological Review, 42, 127-152.

WOODWORTH, R. S., \& SCHLOSBERG, H. (1954). Experimental psychology. New York: Holt.

(Manuscript received March 13, 1989.) 